\title{
3D electric field computation of a composite cross-arm
}

DOI:

10.1109/ELINSL.2012.6251511

Link to publication record in Manchester Research Explorer

\section{Citation for published version (APA):}

Peesapati, V., Zachariades, C., Li, Q., Rowland, S. M., Cotton, I., Allison, F., \& Chambers, D. (2012). 3D electric field computation of a composite cross-arm. In 2012 IEEE International Symposium on Electrical Insulation (ISEI) (pp. 464-468) https://doi.org/10.1109/ELINSL.2012.6251511

\section{Published in:}

2012 IEEE International Symposium on Electrical Insulation (ISEI)

\section{Citing this paper}

Please note that where the full-text provided on Manchester Research Explorer is the Author Accepted Manuscript or Proof version this may differ from the final Published version. If citing, it is advised that you check and use the publisher's definitive version.

\section{General rights}

Copyright and moral rights for the publications made accessible in the Research Explorer are retained by the authors and/or other copyright owners and it is a condition of accessing publications that users recognise and abide by the legal requirements associated with these rights.

\section{Takedown policy}

If you believe that this document breaches copyright please refer to the University of Manchester's Takedown Procedures [http://man.ac.uk/04Y6Bo] or contact uml.scholarlycommunications@manchester.ac.uk providing relevant details, so we can investigate your claim.

\section{OPEN ACCESS}




\section{$3 D$ Electric Field Computation of a Composite Cross-Arm}

\author{
V. Peesapati*, C. Zachariades, Q. \\ Li, S. M. Rowland, I. Cotton, \\ P.R.Green School of Electrical \\ and Electronics Engineering, The \\ University of Manchester, United \\ Kingdom \\ *E-Mail \\ v.peesapati@manchester.ac.uk
}

\author{
F Allison \\ UMIP \\ The University of Manchester, \\ United Kingdom \\ D. Chambers \\ EPL Composite Solutions, United \\ Kingdom
}

\begin{abstract}
The use of composite insulators for overhead transmission lines has increased in the past decade. Various designs and models are now available for a wide range of voltages. The 3D Finite Element Analysis electric field distribution of such composite insulators has been of considerable interest due to its differences to 'conventional' glass or ceramic insulators. Results of such analysis are now widely available. The present paper presents and analyses the electric field distribution around a composite insulator, which is intended to replace both existing high voltage insulators and the cross-arms of transmission towers. The complex geometry of the composite cross-arm, which includes four separate insulator strings and different shed profiles across these members all connected to a common metallic nose cone, make it difficult to model in any 3D Finite Element Analysis package. The present paper will evaluate the electric fields on such a composite cross-arm, in regards to the areas of high field enhancement.
\end{abstract}

Keywords-composite cross-arm, Insulators, Electric field analsyis, Finite element analysis

\section{INTRODUCTION}

Modern day electrical power transmission is taking a giant leap in modernization, with change in power generation and demand. New renewable generation on the system, means that the transmission system will need to be 'smart' to cope with this change. Governments are very keen on upgrading the existing transmission lines to cope with this new demand and change on the networks. One of the challenges that modernization of electrical transmission lines presents is the need to increase power transfer in existing overhead transmission lines. There are two methods by which the capacity of power transmission can be readily increased: retensioning and re-conductoring. Re-tensioning involves allowing additional conductor sag to increase the thermal rating of an existing line. This increases the development of annealing and high temperature creep, due to increased operating temperatures and additional current, resulting in risk of mechanical failure, elongation of cables and decrease of clearance to ground [1].

Re-conductoring involves the replacement of existing cables with conductors of larger power capacity, thereby increasing the power transfer capacity of the system. These systems allow the increase in thermal power rating without compromising the mechanical strength.[2,3]. Another option is to increase the voltage of existing lines, although this is not an easy task to perform on existing steel lattice towers.

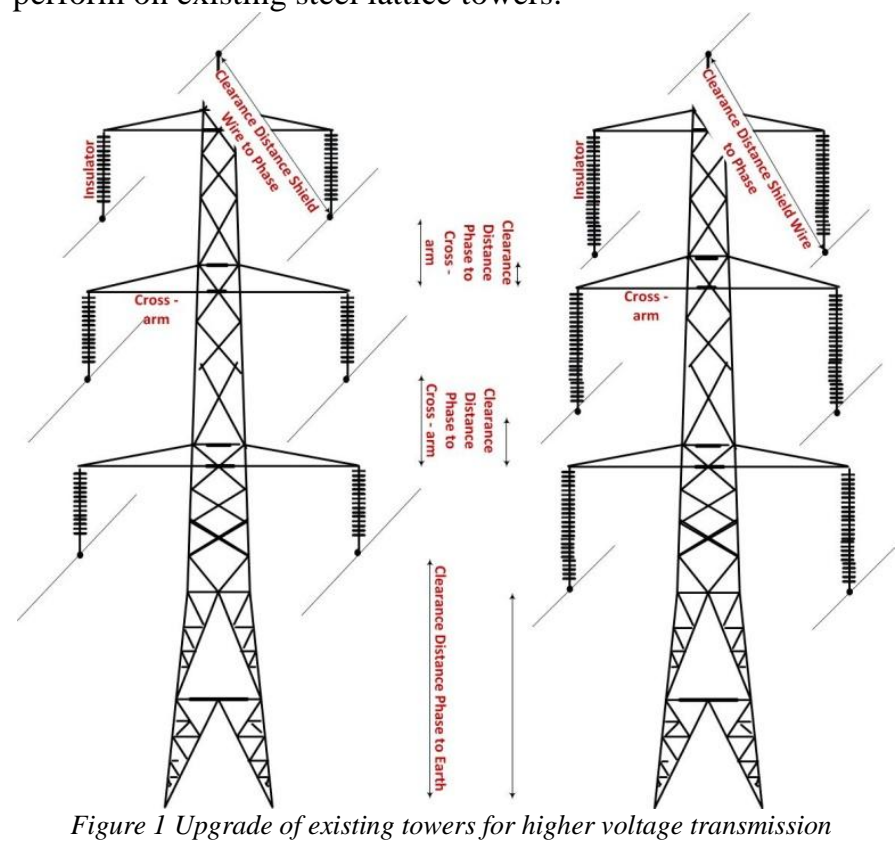

One of the main concerns whilst upgrading existing transmission lines for higher voltages is clearance distances. The problem can be understood from Figure 1. The clearance distances between the high voltage conductors and the ground (ground clearance) is maintained by the insulator. Similarly the clearance distance between the conductors and the cross-arm is maintained by the insulators too. Both these distances are vital and most towers are designed to satisfy these criteria without significant margin.

To upgrade the lines to higher voltages, would basically mean the introduction of longer insulator strings as seen from the tower on the right in Figure 1. From the figure a new area of concern arises, because the ground clearance decreases due to the introduction of a longer insulator string for the cables 
operating at higher voltages, and so does the distance between the cross-arm and the conductor. Another area that needs to be addressed is the maximum clearance whilst an insulator is swinging towards the tower, due to side winds. This is illustrated in figure 2 .

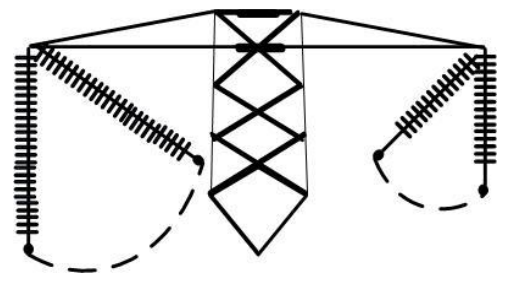

Figure 2 Risk of flashover due to swing

The increase in length of insulator string, increases the risk of flashover in case of swing. More detail can be found in [3].

The present paper deals with a solution that could possibly overcome these drawbacks, whilst still being capable of being used on existing steel transmission towers. The composite cross-arm that is described in this paper is manufactured and being developed by Arago Technology. The authors have previously introduced this composite cross-arms on existing towers [4]. There is also ongoing electrical testing of the crossarms on a coastal trial facility[5].

The composite cross-arms will replace the insulator strings and the steel lattice cross-arm, thus increasing the clearance to ground. This is shown in figure 3.

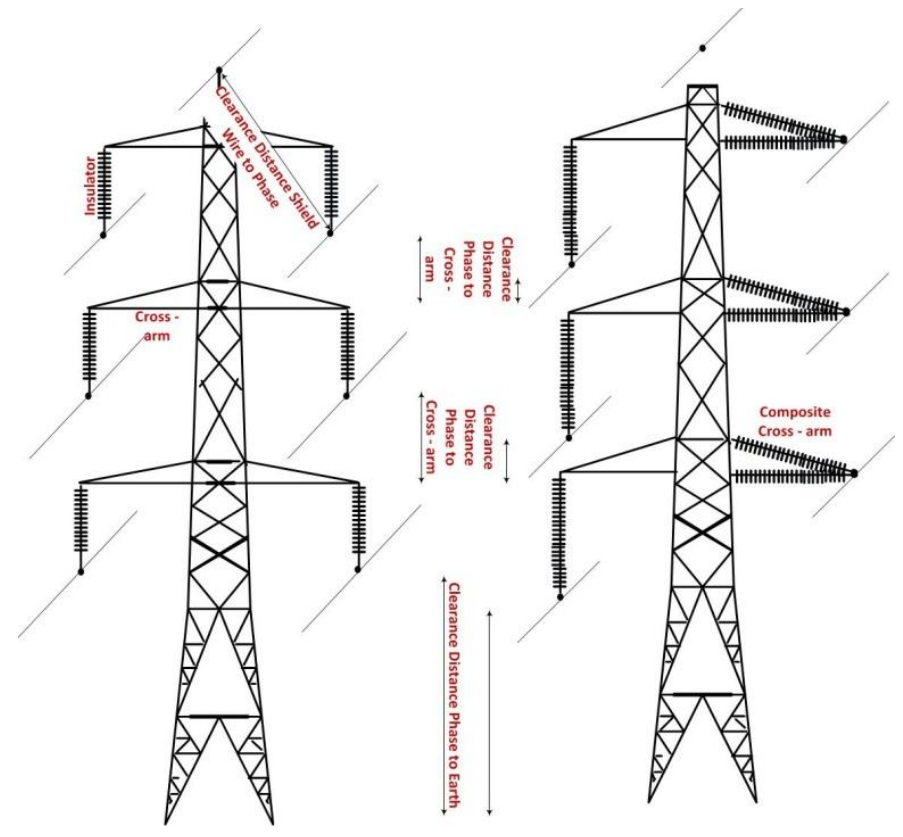

Figure 3 Clearance Comparison (String Insulator vs. Composite Cross-arm)

Whilst Figure 3 shows an improvement in the clearance distances, it must be highlighted that the composite cross-arm will have to still meet standards [6-8] in achieving clearance distances both to the tower and between phase conductors. These distances have been highlighted in [3] and are explained more in detail therein. This paper describes calculations of the electric field distribution on the cross-arm itself.

\section{CROSS-ARM DESIGN}

The composite cross-arm that is intended to replace the insulator strings and the steel lattice cross-arms, needs to be mechanically strong to cope with the compression and tension forces that would be seen on conventional insulator strings and steel cross-arms. The composite cross-arms being analysed in this paper have been designed for these mechanical demands.

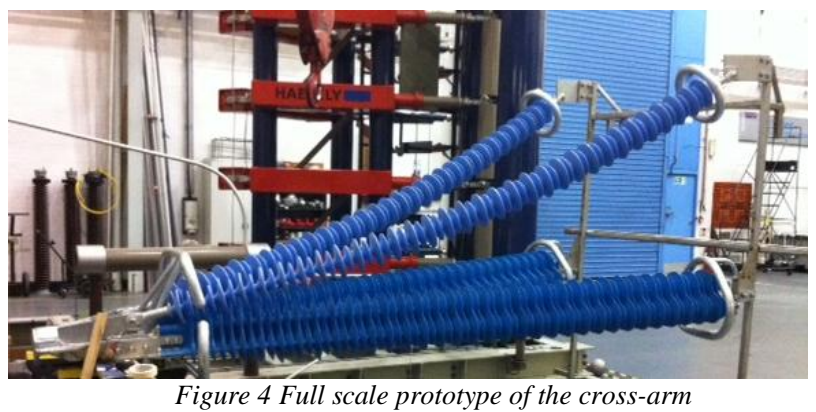

Figure 4 shows a full scale model of a composite cross-arm. The composite cross-arm can be divided into two parts, the tension members (thin, composite insulator string, angled from the horizontal) and the compression members (horizontal, thick, composite insulator string). All four members are connected to a nose cone which will be connected to the high voltage cable and energized at the respective voltage level. The other legs of the four members are designed in such a way that they can be retrofitted onto existing transmission towers.

\section{3D ELECTRIC FIELD ANALYSIS OF INSULATORS}

It is crucial to evaluate electric fields as they have a short-term performance and long-time ageing effects on the insulators. Short-term effects include flashover, which is a temporary failure of an insulator. High electric fields on insulator strings can also cause corona at triple junctions and interfaces, which can, over time, cause degradation of the insulator surface and eventually lead to insulator failure. High electric fields can also cause dry-band arc formation when an insulator is covered in pollution, which also generates accelerated ageing and potentially flashover.

The use of 3D Finite Element electric field analysis for field distribution on insulators is now a common practice, where it used to optimize corona ring placements, reduction of hot spots and design of end connectors. The use of 3D Finite Element analysis for electric field distribution on insulators can be found in [9-12]. Analysis and studies that have been performed in previous studies have usually been on simple composite string insulators. The present paper considers the electric field distribution across the composite cross-arm, which as an assembly consists of four different insulator strings, with minimal symmetry.

Electric fields on an insulator are a factor of [10]:

- $\quad$ Energized voltage

- Geometric shape and design, including corona rings placement and end fittings

- Tower design 
- Environmental conditions

- Material Properties

Thus it is important to take all these factors into consideration whilst designing insulators. These criteria are basically used as design parameters, in order to maintain any local electric field enhancement to levels where corona/partial discharge on the surface is minimized, reducing localized damage. The criteria that are usually followed in designing composite cross-arms are highlighted below. These are extracted from different parts of literature, standards and technical reports. These criteria have been adapted for the composite cross-arm.

Criterion 1: The average field gradient parallel to the insulator cores is no greater than for conventional composite insulators. In the case of the cross-arm this would need to be for all four member insulators, or the complete dry cross-arm with stress relief devices. At $0.5 \mathrm{~mm}$ from insulation surface, the E field rms magnitudes to be less than $4.5 \mathrm{kV} / \mathrm{cm} \mathrm{[13]} \mathrm{.}$

Criterion 2: The local field on metal fittings to be below corona inception values $30 \mathrm{kV} / \mathrm{cm}$. This would include all the end connectors, nose cone and stress relief devices [14-16].

Criterion 3: Fields within dielectrics (core and sheds) to be less than $30 \mathrm{kV} / \mathrm{cm} \mathrm{[10].}$

It must be highlighted that all the above criteria have been adapted based on dry operational conditions. These values will be significantly lower for wet conditions. One other area to be considered is the fields at triple junctions, especially areas where the sheds meet the core and joints between metallic assembly and the insulator material. Further research is required to calculate fields in wet conditions and this is being pursued as the next step in this research.

\section{3D COMPOSITE CROSS-ARM MODEL}

The present model has been designed based on the dimensions of the cross-arm that is being developed for $400 \mathrm{kV}$ application. The model was built on a commercially available CAD package. It is later uploaded into Comsol Finite Element Analysis package, where the electric field analysis has been performed.

Figure 5 shows the composite cross-arm suspended in a block of air. The present simulation is based on connecting a $400 \mathrm{kV}$ conductor to the composite cross-arm The boundary conditions thus applied to the high voltage end of the composite cross-arm is $400 \mathrm{kV}$. All metallic connections at the high voltage end of the composite cross-arm have been set to this potential including the corona rings. The end connections of the composite cross-arm are set to ground potential, as these ends are physically connected to the lattice tower.

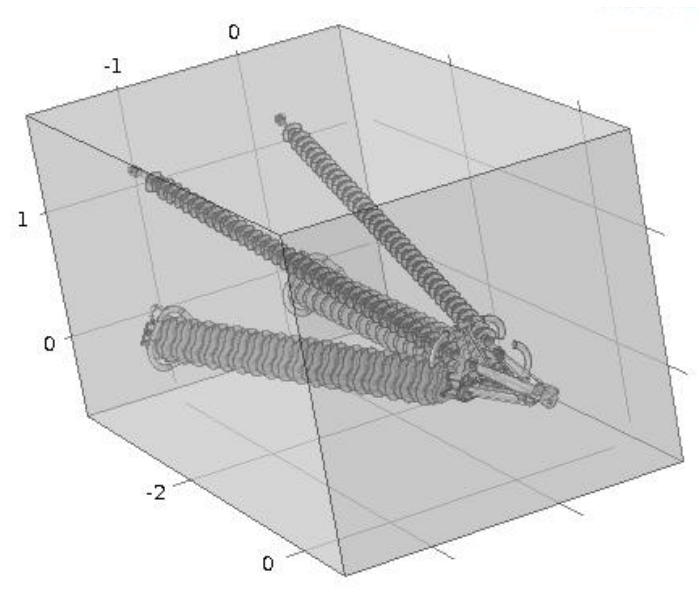

Figure 5 Model of 3D Composite Cross-arm

\section{RESULTS}

For each of the criteria, an example of the compression member and a tension member are analyzed.

\section{A. Criterion 1}

The average field gradient on the tension members and the compression members has been computed. The field plots that are shown below are analyzed $0.5 \mathrm{~mm}$ from the top of the largest shed of the insulator members. The largest shed on the horizontal member is highlighted in Figure 6.

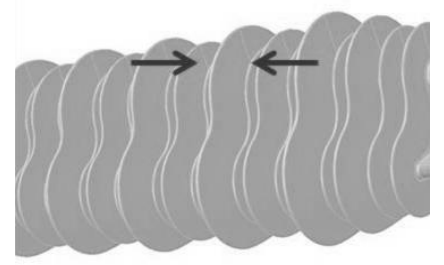

Figure 6 largest shed on compression member

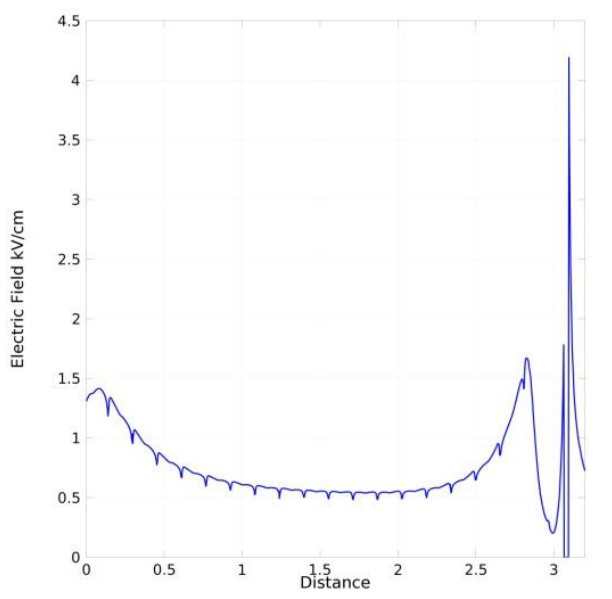

Figure 7 Electric field above sheds - Compression Member 


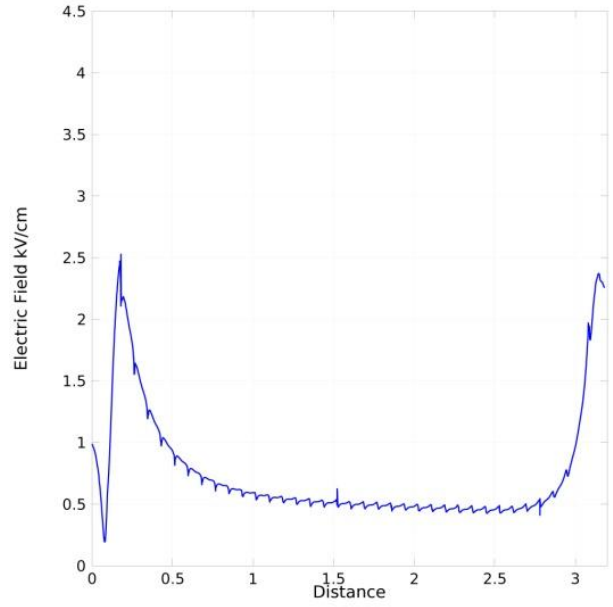

Figure 8 Electric field above sheds - Tension Member

Figure 7 and Figure 8 show the electric field above the sheds on both the compression and tension member. It can be seen that the field above the sheds is within the stated criterion. The spikes in the electric field, are those when the plot runs across the corona ring and the end fittings. There is a sudden drop in the field towards the earth end of the compression member, which can be explained by the fact that the compression member has a corona ring installed at the end whilst this is not present on the tension members.

\section{B. Criterion 2}

Corona is one of main causes for long term ageing on composite insulators. Corona hot spots are generally seen near triple junctions and also metallic fittings with sharp geometric features. In the present model, the main metallic fittings can be identified as the nose cone, end fittings on both type of insulators and the stress relief devices.

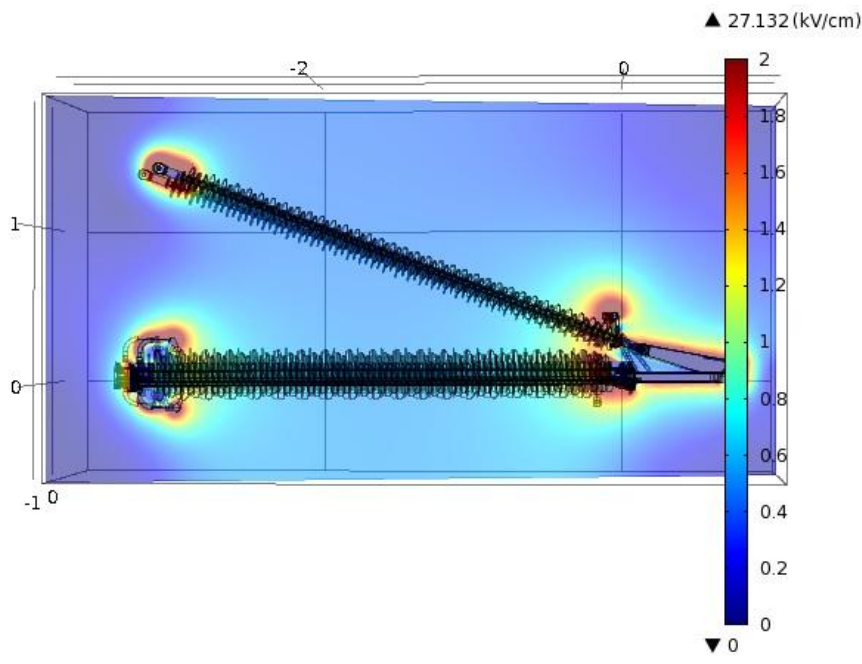

Figure 9 Field Patch through end fittings, nose cone and stress relief assembly

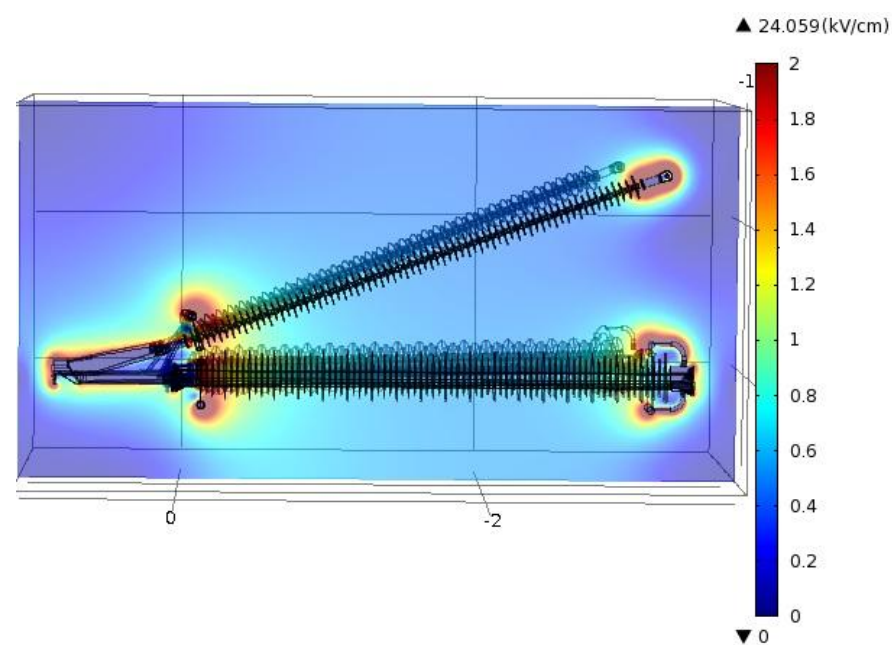

Figure 10 Field Patch through end fittings, nose cone and stress relief assembly

The field plot in Figure 9 shows that the highest electric field across this patch is less than the stipulated $30 \mathrm{kV} / \mathrm{cm}$. A similar result was seen for the other pair of insulating members and is shown in Figure 10. This indicates that there is a difference in the performance of the electric field enhancement across the high voltage end with the stress relief assembly.

\section{Criterion 3}

The fields within the dielectrics will show if there is a possible risk of breakdown within the solid dielectric. To be able to check the electric field through all the sheds, the field on a line $0.5 \mathrm{~mm}$ from the top of the core of the insulating members was plotted, thus running through every shed.

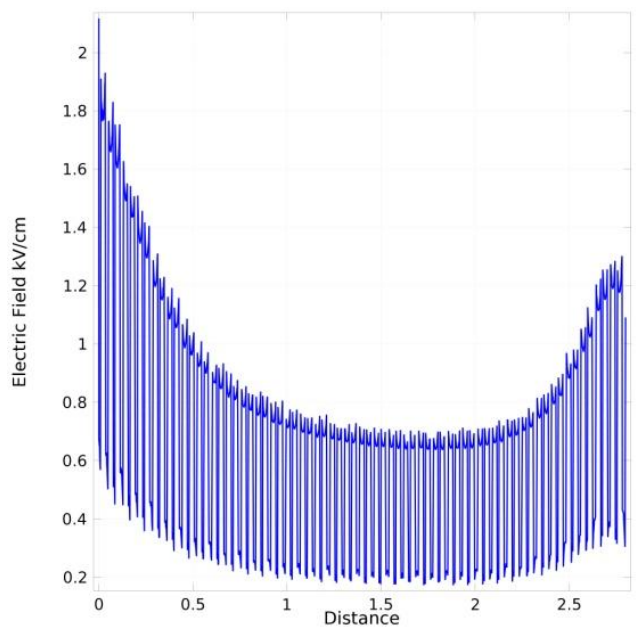

Figure 11 Electric field through the sheds (compression member) 


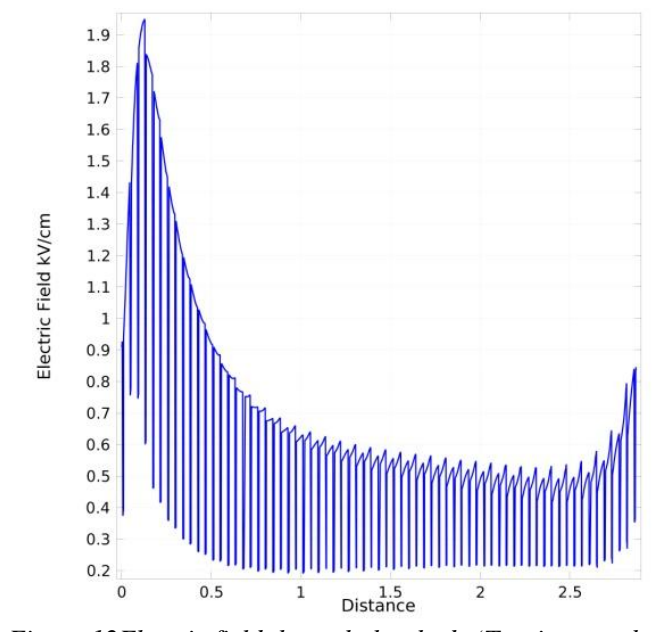

Figure 12Electric field through the sheds (Tension member)

Figure 11 and Figure 12 show the field plots through the sheds of the insulating members. The fields that have been plotted here are well within the range specified, that is, less than 30 $\mathrm{kV} / \mathrm{cm}$. There is a peak rise in the field, seen both at the high voltage end and the earth end of the insulator members. But even with this sharp rise, the fields are within the specified limits.

\section{CONCLUSIONS}

The three criteria on which the present analysis has been performed, have been satisfied. This demonstrates that the idea of the composite cross-arm is a possible solution for upgrading of existing transmission towers. Further work is required to model how the composite cross-arm will perform in wet conditions, and this is ongoing activity. It is under wet and polluted conditions where the composite insulators experience greatest electric stress, and this will be key to satisfying the design parameters that are widely accepted by electrical utilities. So far, the models have shown composite cross-arms can operate under conditions found to be acceptable for conventional composite insulators.

\section{ACKNOWLEDGMENT}

The authors would like to acknowledge the support of Scottish and Southern Energy, National Grid and EPL Composites in the above work.

\section{REFERENCES}

[1] I. Albizu, A. J. Mazon, and I. Zamora, "Methods for increasing the rating of overhead lines," in Power Tech, 2005 IEEE Russia, 2005, pp. 1-6.

[2] K. Kopsidas and S. M. Rowland, "A Performance Analysis of Reconductoring an Overhead Line Structure," Power Delivery, IEEE Transactions on, vol. 24, pp. 2248-2256, 2009.

[3] K. Kopsidas, S. M. Rowland, M. N. R. Baharom, and I. Cotton, "Power transfer capacity improvements of existing overhead line systems," in Electrical Insulation (ISEI), Conference Record of the 2010 IEEE International Symposium on, 2010, pp. 1-5.

[4] C. Zachariades, S. M. Rowland, I. Cotton, P. Green, R. Veerappan, and D. C.A. Chambers, "A Trial Installation of High Voltage Composite Cross-arms," presented at the XVII International Symposium on High Voltage Engineering, Hannover, 2011.

[5] C. Zachariades, I. Cotton, S. M. Rowland, V. Peesapati, P. R. Green, D. Chambers, and M. Queen, "A Coastal Trial Facility for High Voltage Composite Cross-arms," presented at the 2012 International Symposium on Electrical Insulation, San Juan, Puerto Rico, 2012.

[6] B. Standards, "60071 - 1 Insulation co-ordination," in Definitions, principles and rules, ed, 2006.

[7] B. Standards, "61865 Overhead lines.," in Calculation of the electrical component of distance between live parts and obstacles. Method of calculation, ed, 2001.

[8] B. Standards, "50341-1Overhead electrical lines exceeding AC $45 \mathrm{kV}$," in General requirements. Common specifications, ed, 2001.

[9] T. Doshi, R. S. Gorur, and J. Hunt, "Electric field computation of composite line insulators up to 1200 kV AC," Dielectrics and Electrical Insulation, IEEE Transactions on, vol. 18, pp. 861-867, 2011.

[10] A. J. Phillips, J. Kuffel, A. Baker, J. Burnham, A. Carreira, E. Cherney, W. Chisholm, M. Farzaneh, R. Gemignani, A. Gillespie, T. Grisham, R. Hill, T. Saha, B. Vancia, and J. Yu, "Electric Fields on AC Composite Transmission Line Insulators," Power Delivery, IEEE Transactions on, vol. 23, pp. 823-830, 2008.

[11] H. El-Kishky and R. S. Gorur, "Electric potential and field computation along AC HV insulators," Dielectrics and Electrical Insulation, IEEE Transactions on, vol. 1, pp. 982-990, 1994.

[12] U. Schumann, F. Barcikowski, M. Schreiber, H. C. Karner, and J. M. Seifert, "FEM Calculation and Measurement of the Electrical Field Distribution of HV Composite Insulator Arrangements," presented at the Cigre, Paris, 2002.

[13] National Grid, "Composite Insulators for Overhead Lines," unpublished|.

[14] M. S. Naidu and V. Kamaraju, High-voltage engineering, Second ed. Delhi: McGraw-Hill, 1982.

[15] N. L. Allen, "High Voltage Engineering and Testing, Edited by H M Ryan," 1994.

[16] E. Kuffel, High Voltage Engineering: Newnes, 2000. 